\title{
Digital Currency Risk
}

\author{
Scott Gilbert ${ }^{1} \&$ Hio Loi ${ }^{2}$ \\ ${ }^{1}$ Department of Economics, Southern Illinois University Carbondale, Carbondale, IL, USA \\ ${ }^{2}$ Department of Accounting, Finance, Economics, and Political Science, The University of Tennessee at Martin, \\ Martin, TN, USA \\ Correspondence: Hio Loi, Department of Accounting, Finance, Economics, and Political Science, The University \\ of Tennessee at Martin, Martin, TN, USA. Tel: 1-731-881-3308. E-mail: hloi2@utm.edu
}

Received: December 11, 2017

Accepted: December 26, 2017

Online Published: January 10, 2018

doi:10.5539/ijef.v10n2p108

URL: https://doi.org/10.5539/ijef.v10n2p108

\begin{abstract}
Digital currencies, such as Bitcoin, have emerged as an alternative form of money, untethered to traditional money and largely unregulated. As such, digital currency represents a wild frontier for investors who might otherwise be shopping for gold or foreign currencies, with serious risks. The present work considers digital currency from a traditional asset pricing perspective. Setting aside risks of seller fraud or currency theft, we examine fluctuation and systematic risk in the price of Bitcoin. From this perspective, Bitcoin does not appear to carry much systematic risk -- despite its high volatility -- and so is a reasonable candidate for inclusion in investors' portfolios. Some illustrative examples suggest that the optimal amount of Bitcoin to include in investor portfolios may be tiny or instead substantial - as high as 21 percent of total financial assets.
\end{abstract}

Keywords: Bitcoin, systematic risk, optimal portfolio

\section{Introduction}

The idea of digital currency, in a broad sense, merges the traditional features of money with the convenience of electronic transactions, the bank debit card being a leading example. However, the public acceptance of electronic banking transactions has made possible the emergence of an alternative form of digital money, not tethered to a bank account or other traditional store of value, whose trustworthiness lies in the computer algorithms that underlie its construction and distribution. On its face, the virtual currency would appear to be uniquely unqualified as a store of value since virtual currency is just that. But "virtual" does not just mean synthesized or projected: the algorithm that generates units of a particular virtual currency - like Bitcoin - can guarantee that the currency remains within some pre-specified range of supply. In the case of Bitcoin, that supply limit is 21 million Bitcoins. This sort of digital currency is both a virtual currency and a cryptocurrency - with computer encryption protecting coin supply and ownership.

Bitcoin is currently the leading example of cryptocurrency, representing about $93 \%$ of the total cryptocurrency market capitalization (Note 1). The price of Bitcoin has fluctuated dramatically. A Bitcoin was \$13.30/USD on January 1, 2013, and it has increased to $\$ 1,147.25 /$ USD on December 4, 2013. The price of Bitcoin recently went down to $\$ 258.97 /$ USD on March 1, 2015. This huge price fluctuation in Bitcoin provides a big opportunity, and risk, to investors. But price fluctuation is not the only risk with Bitcoin and other cryptocurrencies. A risk of theft exists, as highlighted in the massive heist of Bitcoins from the Mt. Gox Bitcoin exchange in the year 2014. Also, with Bitcoin a highly technical area, nave buyers of Bitcoins face a relatively high probability of fraud by unscrupulous sellers, as recently emphasized by the U.S. Securities and Exchange Commission.

The present work considers digital currency from a traditional asset pricing perspective. In the bulk of our analysis, we set aside risks of seller fraud and theft, much as one does when considering markets for gold or foreign currency. We examine fluctuation and systematic risk in the price of Bitcoin. For unsophisticated investors, huge price fluctuation may seem risky to them. However, a sophisticated investor probably would not put all of his or her eggs in one basket because they want an investment portfolio as diverse as possible to minimize the risks. They look for assets whose values are not affected by the market movement. If the price of an asset follows the fluctuation of the market, it is called a systematic risk asset. Otherwise, it is called a non-systematic risk asset. Thus, if Bitcoin is a non-systematic risk asset, sophisticated investors will still love to invest in it. Therefore, one of the research questions in this study is to examine if Bitcoin has a systematic risk. 
In general, investors can allocate their wealth between risky and riskless assets. However, within the risky assets, investors need to decide how much money should be invested in each risky asset. For the sake of simplicity, assume investors can only allocate their money in between Bitcoin and the stock market as a whole, not individual stock. Given the huge price fluctuation in Bitcoin, Bitcoin may be a good tool for hedging risk. In other words, Bitcoin will be able to diversify the risk in an investment portfolio if it does not have a systematic risk. To test the systematic risk of Bitcoin, the Capital Asset Pricing Model (CAPM) and the Fama-French Three Factors Model are applied. Another question that this study tries to answer is: what proportion of Bitcoin should be included in an investment portfolio? Mean-variance portfolio analysis is used to identify the optimal proportion of Bitcoin in an investment portfolio.

The results of the CAPM suggested that the sensitivity between Bitcoin excess return and excess market return is inelastic. Moreover, the results of the Fama-French Three Factors Model show that Bitcoin excess return cannot be explained by the three variables in the model: excess market return, Small Minus Big (SMB) (Note 2) and High Minus Low (HML) (Note 3). Thus, both the CAPM and the Fama-French Three Factors Model confirm that Bitcoin does not have a systematic risk. The results from a mean-variance portfolio analysis suggest that an optimal risky portfolio should include around $4.4 \%$ to $21.5 \%$ of Bitcoin.

For the robustness tests, we first re-estimate all the analyses using another data sources for Bitcoin's prices. Second, we construct an agent's wealth index for measuring the excess market return. Agents are allowed to allocate their wealth to three different risky assets: bonds, stocks and real estate. Third, instead of using average Bitcoin's prices, we re-estimate our models focusing on the price of Bitcoin from a single Bitcoin exchange company, Bitstamp. Fourth, we included the probability of Bitcoin theft into our models. Moreover, we compare the results of Bitcoin and Gold in the CAPM and the Fama-French Three Factors model. We found that excess Gold return does have a systematic risk. Thus, the movement of Bitcoin's prices does not behave like the traditional assets such as gold. Last but not least, we incorporate Bitcoin into the market portfolio, and the weight of Bitcoin depends on the ratio of Bitcoin capitalization and stock markets capitalization. The results of robustness tests suggest that the Bitcoin does not have systematic risk, and the optimal proportion of Bitcoin in an investment portfolio is almost identical to the main results.

\section{Literature Review}

Moore and Christin (2013) examine the track record of 40 Bitcoin exchanges. They find that less popular exchanges are more likely to shut down than popular ones, but popular exchanges are more likely to suffer a security breach. Briere, Oosterlink, and Szafarz (2013) analyze a Bitcoin investment with a diversified portfolio. They find that an investment portfolio with Bitcoin has a higher average return and volatility compared to an investment portfolio without Bitcoin, and Bitcoin has low correlation with other assets. Their results suggest that well-diversified portfolios with small proportions of Bitcoin may significantly improve the risk-return characteristics. Dyhrberg (2016a) studies the financial asset capabilities of Bitcoin using generalized autogressive conditional heterosdedasticity (GARCH) model and exponential GATCH) model. Bitcoin can be used as a tool for risk-averse investors in anticipation of bad news. In addition, Bitcoin includes the partial advantages of both commodities and currencies in the financial market, so he concludes that Bitcoin is a useful tool for portfolio management risk analysis and market sentiment analysis. Dyhrberg (2016b) studies the hedging capabilities of Bitcoin using the asymmetric GARCH methodology. Bitcoin can be used as a hedge against stock in the Financial Times Stock Exchange index and the US dollar. Thus, Bitcoin has positive contributions in the market for portfolio analysis and risk management.

The most common question people may ask about Bitcoin is whether it is a currency or not. Chen and Pandey (2014) examine the role of Bitcoin as a currency and its usefulness as an investment asset. They compare the correlation between Bitcoin and major world currencies. They found that all major world currencies are significantly correlated with each other, but the correlations between Bitcoin and all major currencies are insignificant. Furthermore, they also found that the correlation between the return from Bitcoin and the return from gold is insignificant. Since the characteristic of Bitcoin is different from other major currencies, they claim that Bitcoin may be less useful as a currency. Furthermore, they measure portfolios efficiency with the Sharpe ratio, the Sortino ratio, and the Omega ratio. Their results show that Bitcoin can enhance the performance of an investor's portfolio.

There is a significant risk on the sustainability of Bitcoin. The Bitcoin user is now enjoying a very low transaction fee. Individual miner and Bitcoin exchange companies charge low transaction fees because they want to increase the number of Bitcoin user. An increased demand for Bitcoin can raise the price of Bitcoin. As a result, Bitcoin miners obtain higher-margin revenue by mining a new Bitcoin. However, when all Bitcoins are 
created, and Bitcoin is widely used. The marginal revenue that received from mining new Bitcoins will disappear, but the miners' margin costs become higher. Since every transaction of Bitcoin would be recorded in Bitcoin network, the distributed ledger requires significant computing power. As a result, the transaction fee needs to rise, so it may cause Bitcoin lost its advantage compared with other fiat currencies (Ali et al., 2014).

\section{Methodology}

The CAPM is used to evaluate the rate of return of an asset correlated to excess market return. The CAPM suggests that a return of an asset equals to the risk-free rate plus the product of risk measure and excess market return. The mathematical expression of the CAPM is as follows:

$$
R_{b, t}=R_{f, t}+\beta\left(R_{m, t}-R_{f, t}\right)
$$

In this study, we modified the CAPM to evaluate Bitcoin excess return instead of just return of Bitcoin. Equation (2) is the modified CAPM, and it is also the equation for the empirical analysis.

$$
R_{b, t}-R_{f, t}=\alpha+\beta\left(R_{m, t}-R_{f, t}\right)+\varepsilon_{t}
$$

Where $R_{b, t}-R_{f, t}$ is Bitcoin excess return; $R_{b, t}$ is the return of Bitcoin, and it is calculated as $R_{b, t}=\left(B P_{t}-\right.$ $\left.B P_{t-1}\right) / B P_{t-1}$; where $B P_{t}$ is the price of Bitcoin in US dollar; $R_{f, t}$ is the risk-free rate; $R_{m, t}-R_{f, t}$ is excess market return which is defined as the market risk, $R_{m, t}$, is subtracted by the risk-free rate. Excess market can also refer as market premium. For the detail of excess market return calculation, see note number (5). $\beta$ is the risk measure. If the estimated value of $\beta$ is significant and larger than 1 , Bitcoin excess return is more volatile than the excess market return. Bitcoin is considered having systematic risk in that case. Or if the estimated value of $\beta$ is insignificant or less than 1 , Bitcoin excess return is unrelated or less volatile than the excess market return. In this case, Bitcoin does not have systematic risk. Subscript $t$ is the time series index; $\varepsilon_{t}$ is the disturbance term.

The Fama-French Three Factors Model is also applied to examine the excess return on Bitcoin. This model is developed by Eugene Fama and Kenneth French. They expand the CAPM by adding two more variables to control the market fluctuation: Small Minus Big (SMB) and High Minus Low (HML). In general SMB captures the different values of small companies and large companies in the market, and HML captures the different price-to-book ratio of small companies and large companies in the market. For the detail of SMB and HML, see notes (2) and (3). As same as in the CAPM, we use Bitcoin excess return as a dependent variable for the Fama-French Three Factors Model. The estimated empirical equation for this model shows below,

$$
R_{b, t}-R_{f, t}=\beta_{0}+\beta_{1}\left(R_{m, t}-R_{f, t}\right)+\beta_{2} S M B_{t}+\beta_{3} H M L_{t}+\tau_{t}
$$

where again $R_{b, t}-R_{f, t}$ is Bitcoin excess return; $R_{m, t}-R_{f, t}$ is excess market return; $S M B_{t}$ is Small Minus Big (SMB); HML $L_{t}$ is High Minus Low (HML); subscript $t$ is the time series index; $\tau_{t}$ is the disturbance term.

Mean-variance portfolio analysis is used to identify the optimal risky portfolio that is how much proportion of Bitcoin should be included in a portfolio. According to the mean-variance portfolio analysis, the optimal risky portfolio can be found by minimizing portfolio variance subject to two constraints. The first constraint sets the level of expected excess return, and the second constraint makes sure that the sum of the portfolio weights is one. The mathematical expression of mean-variance portfolio analysis shows below:

$$
\begin{gathered}
\text { Min } w^{\prime} \sum w \text { subject to } \\
\bar{z}^{\prime} w=\mu \\
1^{\prime} w=1
\end{gathered}
$$

where $w$ is a vector of portfolio weights; $\sum$ is the variance-covariance matrix of excess returns; $\bar{z}$ is a vector of expected excess returns on Bitcoin and market; $\mu$ is the expected return in minimum-variance portfolio. After minimizing equation (4) subject to the two constraints, the optimal weights of risky assets can be found as:

$$
w=\frac{\Sigma^{-\mathbf{1}}\left(\boldsymbol{\mu}-R_{f} \mathbf{1}\right)}{\mathbf{1}^{\prime} \Sigma^{-\mathbf{1}}\left(\boldsymbol{\mu}-R_{f} \mathbf{1}\right)}
$$

where $R_{f}$ is the risk-free rate. The mathematical proof can be found in Ingersoll, Theory of Financial Decision Making (1987, pp. 88-89). In this study, equation (7) is used to calculate the optimal proportion of Bitcoin in an investment portfolio.

\section{Data}

This study observes Bitcoin excess return from 7/20/2010 to 6/30/2014. Data is obtained from two sources: Coindesk.com website and Professor Kenneth R. French's website (Note 4). The prices of Bitcoin in US Dollar 
are obtained from Coindesk.com. In Coindesk.com, the price of Bitcoin is a simple average of Bitcoin to US dollar exchange prices from four exchange companies: Bitfinex, Bitstamp, BTC-e, and LakeBTC. We use Bitcoin daily closed price, but the closed prices on Saturdays, Sundays, and U.S. public holidays are dropped because other variables are not available for those days.

Another data source is from Professor French's website. It provides all the required variables for the Fama-French Three Factors Model, such as the market premium (Note 5), Small Minus Big (SMB), and High Minus Low (HML). In this study, we refer the market premium as the excess market return. Furthermore, Professor French's website also provides these three variables in different regions in the world: global market, European market, Japan market, North American market, global market but exclude the US, and Asia Pacific market exclude Japan (See appendix A for the countries that include in the different regions). Since Bitcoin is traded all over the world, the CAPM and the Fama-French Three Factors model are applied to all those regions, too. However, Professor French's website only provides monthly data for regions that are outside the U.S. Therefore, for the analyses outside the U.S. market, the monthly data is used in the CAPM and the Fama-French Three Factors model between the period of 8/2010 and 7/2014.

Table 1. Summary statistics

\begin{tabular}{lccccc}
\hline Variables & Obs. & Mean & Std. Dev. & Min. & Max. \\
\hline$R_{b, t}-R_{f, t}$ & 994 & 1.242 & 8.323 & -36.24 & 64.82 \\
$R_{m, t}-R_{f, t}$ & 995 & 0.0763 & 1.029 & -6.960 & 4.980 \\
$S M B_{t}$ & 995 & 0.00647 & 0.501 & -1.920 & 3.560 \\
$H M L_{t}$ & 995 & 0.00120 & 0.379 & -1.340 & 1.690 \\
\hline
\end{tabular}

Table 2. Correlation matrix

\begin{tabular}{lcccc}
\hline & $R_{b, t}-R_{f, t}$ & $R_{m, t}-R_{f, t}$ & $S M B_{t}$ & $H M L_{t}$ \\
\hline$R_{b, t}-R_{f, t}$ & 1 & & & \\
$R_{m, t}-R_{f, t}$ & 0.0544 & 1 & & \\
$S M B_{t}$ & 0.0437 & 0.510 & 1 & \\
$H M L_{t}$ & 0.0537 & 0.133 & -0.105 & 1 \\
\hline
\end{tabular}

Table 1 reports summary statistics, and Table 2 shows the correlation matrix among the variables. Both Tables are the daily data in the U.S. market. The fluctuation of Bitcoin excess return is much bigger than the excess market return in the U.S. market. The mean value and the standard deviation of Bitcoin excess return are 1.24 and 8.32, respectively, whereas the mean value and the standard deviation of the excess market return in the U.S. market are 0.08 and 1.03, respectively. The correlations between Bitcoin excess return and other variables are tiny. These small correlations suggest that Bitcoin should have a less systematic risk.

\section{Results and Discussion}

Table 3. Excess Bitcoin return in the U.S. (using data from Coindesk.com)

\begin{tabular}{lcc}
\hline & $(1)$ & $(2)$ \\
& CAPM & FF-3f model \\
\hline$R_{m, t}-R_{f, t}$ & $0.440^{*}$ & 0.242 \\
& $(1.72)$ & $(0.80)$ \\
$S M B_{t}$ & & 0.564 \\
& & $(0.90)$ \\
$H M L_{t}$ & & 1.170 \\
& & $(1.63)$ \\
Constant & $1.208^{* * *}$ & $1.218^{* * *}$ \\
& $(4.57)$ & $(4.61)$ \\
Observations & 994 & 994 \\
R-squared & 0.00 & 0.01 \\
\hline
\end{tabular}

Dependent variables are excess Bitcoin returns. $t$ values are in parentheses.

$* * * \mathrm{p}<0.01, * * \mathrm{p}<0.05, * \mathrm{p}<0.1$ 
Table 3 shows the estimated results of the CAPM and the Fama-French Three Factors Model in the U.S. market. Column (1) is the results of the CAPM, and Column (2) is results of the Fama-French Three Factors Model. In the CAPM, the coefficient of the U.S. excess market return is less than one and positively significant at 10 percentage level; this coefficient means that a $1 \%$ increase in excess market return leads to $0.44 \%$ increases in Bitcoin excess return. As a result, Bitcoin excess return is less volatile than the market; Bitcoin is considered a non-systematic risk asset. In the Fama-French Three Factors Model, all three variables are insignificant, so the change of Bitcoin excess return cannot be explained by excess market return, SMB and HML variables. The results from the two models support each other. Both models conclude that Bitcoin does not have a systematic risk. Therefore, the results suggest that Bitcoin can be used to hedge the market fluctuation. In other words, Bitcoin can be used to diversify the risk in an investment portfolio. These results support the findings in Briere, Oosterlink, and Szafarz (2013). They find that well-diversified portfolios with small proportion of Bitcoin may significantly improve the risk-return characteristics.

Table 4. Excess Bitcoin return (using monthly data from Coindesk.com)

\begin{tabular}{|c|c|c|c|c|c|c|c|c|}
\hline & \multicolumn{2}{|c|}{ The U.S. } & \multicolumn{2}{|c|}{ Asia Pacific $^{+}$} & \multicolumn{2}{|c|}{ Europe } & \multicolumn{2}{|c|}{ Global $^{++}$} \\
\hline & CAPM & FF-3f model & CAPM & FF-3f model & CAPM & FF-3f model & CAPM & FF-3f model \\
\hline \multirow{2}{*}{$R_{m, t}-R_{f, t}$} & -0.156 & -1.338 & -1.370 & -1.689 & -1.073 & -0.858 & -0.664 & -0.476 \\
\hline & $(0.05)$ & $(0.33)$ & $(0.61)$ & $(0.71)$ & $(0.48)$ & $(0.31)$ & $(0.25)$ & $(0.16)$ \\
\hline \multirow{2}{*}{$S M B_{t}$} & & 4.496 & & -8.380 & & -0.378 & & -0.294 \\
\hline & & $(0.60)$ & & $(1.31)$ & & $(0.05)$ & & $(0.03)$ \\
\hline \multirow{2}{*}{$H M L_{t}$} & & -6.695 & & -2.193 & & -0.905 & & -2.293 \\
\hline & & $(0.87)$ & & $(0.29)$ & & $(0.15)$ & & $(0.28)$ \\
\hline \multirow{2}{*}{ Constant } & $36.80 * * *$ & $38.52 * * *$ & $37.98 * * *$ & $36.65 * * *$ & $37.81 * * *$ & $37.53 * * *$ & $37.24 * * *$ & $37.45 * * *$ \\
\hline & $(2.81)$ & $(2.85)$ & (3.11) & $(2.90)$ & $(3.08)$ & $(2.93)$ & $(3.02)$ & $(2.95)$ \\
\hline Observations & 47 & 47 & 47 & 47 & 47 & 47 & 47 & 47 \\
\hline \multirow[t]{3}{*}{ R-squared } & 0.00 & 0.04 & 0.01 & 0.05 & 0.01 & 0.01 & 0.00 & 0.00 \\
\hline & \multicolumn{2}{|c|}{ Global } & \multicolumn{2}{|c|}{ Japan } & \multicolumn{2}{|c|}{ North America } & & \\
\hline & CAPM & FF-3f model & CAPM & FF-3f model & CAPM & FF-3f model & & \\
\hline \multirow{2}{*}{$R_{m, t}-R_{f, t}$} & -0.509 & -0.149 & 3.900 & 3.885 & -0.208 & -0.860 & & \\
\hline & $(0.17)$ & $(0.05)$ & $(1.27)$ & $(1.71)$ & $(0.06)$ & $(0.22)$ & & \\
\hline \multirow{2}{*}{$S M B_{t}$} & & 1.780 & & -1.804 & & 2.946 & & \\
\hline & & $(0.18)$ & & $(0.30)$ & & $(0.38)$ & & \\
\hline \multirow{2}{*}{$H M L_{t}$} & & -7.255 & & -1.851 & & -8.974 & & \\
\hline & & $(0.79)$ & & $(0.24)$ & & (1.13) & & \\
\hline \multirow{2}{*}{ Constant } & $37.20 * * *$ & $37.91 * * *$ & $33.15 * * *$ & $33.94 * *$ & $36.86 * * *$ & $39.15 * * *$ & & \\
\hline & (2.94) & $(2.95)$ & (2.73) & $(2.69)$ & (2.84) & $(2.90)$ & & \\
\hline Observations & 47 & 47 & 47 & 47 & 47 & 47 & & \\
\hline R-squared & 0.00 & 0.02 & 0.03 & 0.04 & 0.00 & 0.04 & & \\
\hline
\end{tabular}

Dependent variables are excess Bitcoin return. t values are in parentheses. $* * * \mathrm{p}<0.01$, ** $\mathrm{p}<0.05$, $* \mathrm{p}<0.1$

${ }^{+}$Japan is excluded in Asia Pacific region. ${ }^{++}$U.S. is excluded in Global region.

Table 4 show the estimated results of the CAPM and the Fama-French Three Factors Model in different regions using monthly data. All the variables are insignificant except the constant terms. Furthermore, all the values of R-squared are extremely small. The CAPM and the Fama-French Three Factors Model are not able to explain Bitcoin excess return, but the results tell us that Bitcoin does not have systematic risks in all major markets around the world.

Table 5. Optimal portfolio using data from Coindesk.com

\begin{tabular}{lccccc}
\hline Panel A (Using daily data): & \multicolumn{1}{l}{} \\
\hline \multicolumn{1}{l}{$\mu_{A}$} & $\operatorname{var}(A)$ & & & & \\
\hline Excess Bitcoin return & 1.242 & 69.270 & & & \\
& $\mu_{B}$ & $\operatorname{var}(B)$ & $\operatorname{cov}(B, A)$ & {$\left[W_{A}\right.$} & $\left.W_{B}\right]$ \\
\hline The U.S. & 0.076 & 1.061 & 0.466 & $21.41 \%$ & $78.59 \%$ \\
\hline
\end{tabular}




\begin{tabular}{|c|c|c|c|c|c|}
\hline \multicolumn{6}{|c|}{ Panel B (Using monthly data): } \\
\hline & $\mu_{A}$ & $\operatorname{var}(A)$ & & & \\
\hline \multirow[t]{2}{*}{ Excess Bitcoin return } & 36.552 & 6669.798 & & & \\
\hline & $\mu_{B}$ & $\operatorname{var}(B)$ & $\operatorname{cov}(B, A)$ & {$\left[W_{A}\right.$} & $\left.W_{B}\right]$ \\
\hline The U.S. & 1.485 & 13.946 & -2.115 & $4.9 \%$ & $95.1 \%$ \\
\hline Asia Pacific ${ }^{+}$ & 0.998 & 28.425 & -39.663 & $11.7 \%$ & $88.3 \%$ \\
\hline Europe & 1.035 & 29.300 & -32.108 & $12.1 \%$ & $87.9 \%$ \\
\hline Global $^{++}$ & 0.949 & 21.023 & -13.998 & $10.3 \%$ & $89.7 \%$ \\
\hline Global & 1.170 & 16.746 & -8.419 & $7.1 \%$ & $92.9 \%$ \\
\hline Japan & 0.800 & 15.32 & -58.913 & $13.6 \%$ & $86.4 \%$ \\
\hline North America & 1.373 & 14.407 & -2.904 & $5.4 \%$ & $94.6 \%$ \\
\hline
\end{tabular}

$A=R_{b, t}-R_{f, t}, B=R_{m, t}-R_{f, t}$ and $\mu_{A}$ is the expect return on excess Bitcoin return.

$\operatorname{var}(A)$ and $\operatorname{var}(B)$ are the variance of excess Bitcoin return and the variance of excess market return.

$\operatorname{cov}(B, A)$ is the covariance of excess market return and excess Bitcoin return.

$\left[W_{A} W_{B}\right]$ is the optimal proportion of Bitcoin and stocks in an investment portfolio.

${ }^{+}$Japan is excluded in Asian Pacific region. ${ }^{++}$U.S. is excluded in Global region.

Table 5 reports the results of mean-variance portfolio analyses. Panel A shows the result in the U.S. market using daily data, the optimal proportion of Bitcoin in an investment portfolio is $21.41 \%$. Panel B shows the results in different regions using monthly data; the results suggest that the optimal proportion of Bitcoin in an investment portfolio is around $4.9 \%$ to $13.6 \%$ depends on the regions. The expected Bitcoin excess return is 1.24 per day and 36.55 per month, and the expected market excess return is only 0.08 per day in the U.S. and between 0.8 and 1.49 depends on different regions.

\section{Robustness Tests}

All the results for robustness tests are reported in the appendix. For robustness tests, we first re-estimate the CAPM and the Fama-French Three Factors Model using different sources of Bitcoin's prices. Bitcoin's prices are obtained from Coindesk.com website in the last section. In the first robustness test, Bitcoin's prices are collected from Oanda.com website. The calculations of Bitcoin's prices are different between Coindesk.com and Oanda.com websites. In Coindesk.com, the price of Bitcoin is a simple average of Bitcoin's prices in the US dollar from four exchange companies: Bitfinex, Bitstamp, BTC-e, and LakeBTC. In Oanda.com, the website claims that the price of Bitcoin is averaged for global foreign exchange markets, but the website does not disclose the detail for the its sources. Moreover, Oanada.com provides only the weekly data for Bitcoin's prices, and its dataset starts from 8/2010. Thus, the sample period in the first robustness test is from the period of 8/2010 and 7/2014. Using the weekly data, the CAPM and the Fama-French Three Factors Model show once again that none of the variables are significant. The results report in Table 6. These results confirm that Bitcoin does not have systematic risk in the U.S. market.

Table 7 show the results of the CAPM and the Fama-French Three Factors Model in different regions using monthly data from Oanada.com. The findings are similar to Table 4 where the data of Bitcoin price is from Coindesk.com. None of the variables are significant across the regions. Therefore, the results of these robustness tests reconfirm our results that Bitcoin has no systematic risk in the U.S. and other regions in the world. Table 8 reports the results of mean-variance portfolio analysis using data from Oanda.com. The optimal proportion of Bitcoin in an investment portfolio is $16.1 \%$ using the U.S. weekly data. However, the optimal proportion of Bitcoin in an investment portfolio drops to around $4.4 \%$ to $12.1 \%$ depends on different regions. These results are similar compared with the results using data from Coindesk.com and Oanda.com. The optimal proportion of Bitcoin in an investment portfolio is higher in high-frequency data.

In above analysis, agents are only allowed to allocate their wealth in between the stock market and Bitcoin since the excess market return that provides from Professor French's website is the value-weighted return from the listed firms in the stock markets. In reality, agents may allocate their wealth to various assets, such as government bonds, corporate bonds, real states, etc. To achieve a more precise analysis of the systematic risk of Bitcoin and the optimal proportion of Bitcoin in an investment portfolio, we construct an agent's wealth index that includes varieties of assets in the market.

In the agent's wealth index, only the risky assets are incorporated because the goal is to estimate the optimal proportion of Bitcoins in a risky portfolio. The agent's wealth index is a weighted average of bonds, stocks and real estate; the weight of these assets is based on the survey of changes in the U.S. family finances from 2010 to 
2013 (Bricker et al., 2014). In the survey, it reports the ownerships of any financial asset in the U.S. families in the year 2010 and 2013. Since some of the financial assets are not considered as risky assets such as certificate of deposit, transaction accounts, and vehicles, we select three assets to represent the risky assets: bonds (Note 6), stocks (Note 7), and real estate (Note 8 ). The weights of these risky assets are $24.75 \%$ in bonds, $8.44 \%$ in stocks, and $66.81 \%$ in real estate in the year 2010 , and $21.57 \%$ in bonds, $10.91 \%$ in stocks, and $67.52 \%$ in real estate in the year 2013. To measure the return of the three risky assets, the growth rate of Moody's seasoned aaa corporate bond yield as a proxy for bonds; excess market return data from professor Fench's website is used again to represent the return on the stocks; and the return of the U.S. real estate market is measured by the growth rate of the FTSE NAREIT US real estate index. Because of the data limitation, the agents' wealth index is constructed only in monthly data for the U.S. market.

Table 9 shows the estimated results of the CAPM and the Fama-French Three Factors model using the agents' wealth index based on the weights of risky assets in the year 2010. The results support our previous results. Both the CAPM and the Fama-French Three Factors model confirm that Bitcoin does not have systematic risk. In panel B, the results suggest that agents should allocate $8.4 \%$ of their wealth on Bitcoin in their portfolio. The difference between Table 10 and Table 9 is the agents' wealth index. The agents' wealth index in the Table 10 follows the weights of risky assets in the year 2013. The results are similar to the Table 9 and Table 10. None of the variables are significant in both the CAPM and the Fama-French Three Factors Model, and the optimal proportion of Bitcoin in an investment portfolio raises from $7.4 \%$ to $8.4 \%$.

Furthermore, instead of using average Bitcoin's prices, we re-estimate our models use the price of Bitcoin from a single Bitcoin exchange company, Bitstamp. The historical transactions data for Bitstamp is obtained from bitcoin charts' website (Note 9). The excess Bitcoin return is again calculated by the growth rate of average daily Bitcoin prices subtract from the risk-free rate. The observation period is between 9/13/2011 and 6/30/2014 because Bitstamp started its business in the year 2011. We, again, re-estimate all the CAPM, the Fama-French Three Factors Model, and mean-variance portfolio analysis replacing the new measurement of excess Bitcoin return, and the results are reported in the Table 11. The results from the CAPM and the Fama-French Three Factors Model confirm the main result that Bitcoin does not have a systematic risk. The optimal proportion of Bitcoin in a portfolio is $12.59 \%$. This percentage is much lower than $21 \%$ which is the result that obtained from using Bitcoin's prices from Coindesk.com. The result still suggests investors to hold a small amount of Bitcoin in their portfolio.

As we mentioned in the introduction, the risk of holding Bitcoin is not limited to systematic risk. Bitcoin holders may expose the risks of theft and fraud. For the risk of fraud, we inquire to the U.S. Securities and Exchange Commission, but we have not received any reply from them. For the risk of theft, we use a simple analysis to estimate the probability of Bitcoin theft. To the best of our knowledge, we found 8 cases of Bitcoin theft. Table 12 shows the value and the number of Bitcoins were stolen in each case. The probability of Bitcoin theft is calculated by the ratio of the total number of Bitcoins theft to the total number of Bitcoins in circulation. The total Bitcoin in circulation was around 14,530,000 BTC in September 2015, and the total number of Bitcoin theft was 785,116.96 BTC. Thus, the probability of Bitcoin theft is 5.4\% $(785,116.96 / 14,530,000 \times 100=5.4 \%)$. As a result, we would claim that the risk of theft in Bitcoin is not high.

After figuring out the probability of Bitcoin theft, we incorporate this information into the mean-variance analysis to estimate the optimal proportion of Bitcoin in an investment portfolio. We assume that there is a certain probability that Bitcoin would be stolen in an investment portfolio, and $P$ represents the probability. The return of the stolen Bitcoin is a negative one. After incorporating this information, the adjusted expected excess Bitcoin return, $E\left[R_{b, t}^{a}-R_{f, t}^{a}\right]$, becomes:

$$
E\left[R_{b, t}^{a}-R_{f, t}^{a}\right]=(-1) P+E\left[R_{b, t}-R_{f, t}\right](1-P)
$$

The risk-free rate is not affected by the probability of Bitcoin theft, so $R_{f, t}^{a}=R_{f, t}$. Based on the adjusted expected excess Bitcoin return, the variance of the adjusted excess Bitcoin return becomes:

$$
\operatorname{Var}\left(R_{b, t}^{a}-R_{f, t}^{a}\right)=E\left[\left(R_{b, t}^{a}-R_{f, t}^{a}\right)^{2}\right]-\left(E\left[R_{b, t}^{a}-R_{f, t}^{a}\right]\right)^{2}
$$

Where $E\left[\left(R_{b, t}^{a}-R_{f, t}^{a}\right)^{2}\right]=(-1)^{2} P+E\left[\left(R_{b, t}-R_{f, t}\right)^{2}\right](1-P)$. The covariance of the adjusted excess Bitcoin return and the excess market return can be obtained from the following equation:

$$
\operatorname{Cov}\left(\left(R_{b, t}^{a}-R_{f, t}^{a}\right),\left(R_{m, t}-R_{f, t}\right)\right)=E\left[\left(R_{b, t}^{a}-R_{f, t}^{a}\right)\left(R_{m, t}-R_{f, t}\right)\right]-E\left[R_{b, t}^{a}-R_{f, t}^{a}\right] E\left[R_{m, t}-R_{f, t}\right]
$$

Where $E\left[\left(R_{b, t}^{a}-R_{f, t}^{a}\right)\left(R_{m, t}-R_{f, t}\right)\right]=(-1)\left(R_{m, t}-R_{f, t}\right) P+\left(R_{b, t}-R_{f, t}\right)\left(R_{m, t}-R_{f, t}\right)(1-P)$. Having the variances and covariance of the adjusted excess Bitcoin return and the excess market return, we re-estimate the optimal proportion of Bitcoin in an investment portfolio using equation (7). The results report in Table 13, and these 
results are very similar to the main results in Table 5. The optimal proportion of Bitcoin in an investment portfolio drops slightly from $21.4 \%$ to $20.3 \%$ after incorporating the probability of Bitcoin theft using daily data. Moreover, the results almost stay the same in the estimation of the optimal proportion of Bitcoin in an investment portfolio using monthly data. Therefore, investors can almost ignore the probability of Bitcoin theft in constructing an investment portfolio.

To see the difference between Bitcoin and traditional asset. We compare the results between Bitcoin and gold in the CAPM and the Fama-French Three Factors Model. The price of gold in London (morning fixing, 1 ounce of fine gold, in term of US dollar) is selected for the comparison; the price of gold is obtained from Quandl.com website. As same as Bitcoin, we use the excess gold return, the growth rate of gold prices subtracts from the risk-free rate. Table 14 shows the results of the CAPM and the Fama-French Three Factors Model for the excess gold return. Excess market return has positively significant impacts on all the regions except Japan. The coefficients of excess market returns are less than 1 , so excess gold return does not have a systematic risk, but the stock market fluctuation does affect the price of gold. Thus, the movement of Bitcoin's prices does not behave like the price in tradition assets such as gold.

According to the definition of the market portfolio, a portfolio consisting all securities in which the proportion invested in each security corresponds to its relative market value. However, our portfolio does not include any proportion of Bitcoin. To overcome this short come, we add Bitcoin into the portfolio, and the proportion of Bitcoin is based on the ratio of Bitcoin capitalization and stock market capitalization. The year 2012 is the latest data for stock markets capitalization around to the world. This data shows in the Table 15. The United States had the biggest stock market capitalization in the world. The data of Bitcoin capitalization is obtained from blockchain.info website. On November 10, 2015, Bitcoin capitalization was 5.4 billion US dollar, and the average value of Bitcoin capitalization in 2012 is 0.0815 billion US dollars. Bitcoin capitalization has increased dramatically from 2012 to 2015 . Table 16 shows the proportion of Bitcoin in the portfolio based on the capitalization data in 2012 and 2015. There may have biases for constructing a market portfolio based on the Bitcoin capitalization in 2015 and stock market capitalization in 2012, but it can give some ideas about what happens if Bitcoin capitalization increases. Table 16 shows the weights of Bitcoin in the market portfolio depends on Bitcoin capitalization in 2012 and November 10, 2015. The column (2) in the Table 16 is the total stock market capitalization on those regions. The names of countries within each region is listed in the appendix.

Tables 17 and 18 report the results of the CAPM and the Fama-French Three Factors Model using daily data with the market portfolio incorporated Bitcoin. The difference between Table 17 and Table 18 is the weight of Bitcoin in the market portfolio. The weight of Bitcoin in the market portfolio is $0.0004 \%$ in the table 17 and $0.0289 \%$ in the table 18, which is based on the Bitcoin capitalization in 2012 and 2015. The results are very similar compared to Table (3), our main results. The excess market return variables are positively significant and less than one in the CAPMs but insignificant in the Fama-French Three Factors Models. The values of R-squared are close to zero. Thus, Bitcoin does not have a systematic risk in the U.S. market.

We apply the two market portfolios to the different regions. Table 19 are based on the market portfolio where Bitcoin is weighted $0.0004 \%$, and table 20 are based on the market portfolio where Bitcoin is weighted $0.0289 \%$. All results suggest Bitcoin does not have systematic risk. Last but not least, we re-do the mean-variance analyses based on the market portfolio where Bitcoin is weighted $0.0004 \%$, and the results are reported in the table 21 . Since the weight of Bitcoin is extremely tiny in the market portfolio, the results stay the same. The optimal proportion of Bitcoin in an investment portfolio is $21.5 \%$ in the U.S. market under the analysis using daily data, and the optimal proportion of Bitcoin in an investment portfolio is around $4.9 \%$ to $13.6 \%$ depends on different regions. Throughout the different robustness tests, the results consistently suggest that Bitcoin does not have a systematic risk, and the optimal proportion of Bitcoin in an investment portfolio is around $4.4 \%$ to $21.5 \%$.

\section{Conclusion}

This study examines the systematic risk of Bitcoin using the CAPM and the Fama-French Three Factors Model between the period 8/2010 and 7/2014. The results suggest that Bitcoin is a non-systematic risk asset around the world markets. These results imply that including Bitcoin in an investment portfolio can diversify its risk wherever the investment is located. In addition, the mean-variance portfolio analyses suggest that the optimal proportion of Bitcoin in an investment portfolio is between $4.4 \%$ to $21.5 \%$.

\section{References}

Ali, R., Barrdear, J., Clews, R., \& Southgate, J. (2014). The economics of digital currency. Bank of England Quarterly Bulletin, 54(3), 276-286. Retrieved from https://econpapers.repec.org/article/boeqbullt/0148.htm 
Bricker, J., Dettling, L. J., Henriques, A., Hsu, J. W., Moore, K. B., Sabelhaus, J., Thompson, J., \& Richard, A. (2014). Changes in U.S. Family Finances from 2010 to 2013: Evidence from the Survey of Consumer Finances. Federal Reserve Bulletin, 100(4). Retrieved from https://www.federalreserve.gov/pubs/bulletin/2014///pdf/scf14.pdf

Brière, M., Oosterlinck, K., \& Szafarz, A. (2015). Virtual currency, tangible return: Portfolio diversification with bitcoin. Journal of Asset Management, 16(6), 365-373. https://doi.org/10.1057/jam.2015.5

Dyhrberg, A. H. (2016a). Bitcoin, gold and the dollar-A GARCH volatility analysis. Finance Research Letters, 16, 85-92. https://doi.org/10.1016/j.frl.2015.10.008

Dyhrberg, A. H. (2016b). Hedging capabilities of bitcoin. Is it the virtual gold? Finance Research Letters, 16, 139-144. https://doi.org/10.1016/j.frl.2015.10.025

Ingersoll, J. E. (1987). Theory of financial decision making (Vol. 3). Rowman \& Littlefield. Retrieved from https://books.google.com/books?hl=en\&lr=\&id=_JTWMD_Cm-QC\&oi=fnd\&pg=PR9\&dq=Ingersoll,+J.+E .+(1987).+Theory+of+financial+decision+making+(Vol.+3).+Rowman+\%26+Littlefield.\&ots=Ee4mlDMA y_\&sig=_ncJatDkq9mcTXC6zKiox0iBPLA\#v=onepage\&q\&f=false

Wu, C. Y., Pandey, V. K., \& DBA, C. (2014). The value of Bitcoin in enhancing the efficiency of an investor's portfolio. Journal of Financial Planning, 27(9), 44-52. Retrieved from https://www.researchgate.net/profile/Vivek_Pandey30/publication/280883667_The_value_of_Bitcoin_in_e nhancing_the_efficiency_of_an_investor's_portfolio/links/55ca6d5b08aea2d9bdcc00d4.pdf

\section{Notes}

Note 1. As of July 1, 2014, according to CoinMarketCap.com.

Note 2. In Fama-French three factors model, Small Minus Big (SMB) is defined as the average return on the three small portfolios minus the average return on the three big portfolios. $S M B=\frac{1}{3}($ Small Value + Small Neutral + Small Growth $)-\frac{1}{3}($ Big Value + Big Neutral + Big Growth $)$

Note 3. In Fama-French three factors model, High Minus Low (HML) is defined as the average return on the two value portfolios minus the average return on the two growth portfolios. $H M L=\frac{1}{2}$ (Small Value + Big Value $)-$ $\frac{1}{2}$ (Small Growth + Big Growth)

Note 4. Dr. French is the Roth Family Distinguished Professor of Finance at the Tuck School of Business at Dartmouth College.

Note 5. According to French's website, the market premium is value-weight return of all Center for Research in Security Prices (CRSP) firm incorporated in the US and list on the New York Stock Exchange (NYSE), American Stock Exchange (AMEX), or NASDAQ that have a CRSP share code of 10 or 11 at the beginning of month $t$, good shares and price data at the beginning of $t$, and good return data for $t$ minus the one-month Treasury bill rate (from Ibbotson Associates).

Note 6. According to the survey, bonds include only those held directly and include corporate and mortgage-backed bonds.

Note 7. According to the survey, stocks include publicly traded stocks that are directly held - that is, corporate equities not held as part of a managed investment account or mutual fund.

Note 8 . Real estate is the sum of the four non-financial assets categories in the survey, and they are primary residence, other residential property, equity in nonresidential property, and business equity. For the detail of each category, see the appendix section.

Note 9. Bitcoin charts' website provides almost all Bitcoin exchange companies historical transaction data, http://api.bitcoincharts.com/v1/csv/

\section{Appendix}

The global factors and portfolios include all 23 countries in the four regions: Australia, Austria, Belgium, Canada, Denmark, Finland, France, Germany, Greece, Hong Kong, Ireland, Italy, Japan, Netherlands, New Zealand, Norway, Portugal, Singapore, Spain, Switzerland, Sweden, United Kingdom, United States.

The Global ex-US factors and portfolios include 22 countries: Australia, Austria, Belgium, Canada, Denmark, 
Finland, France, Germany, Greece, Hong Kong, Ireland, Italy, Japan, Netherlands, New Zealand, Norway, Portugal, Singapore, Spain, Switzerland, Sweden, United Kingdom.

The European factors and portfolios include Austria, Belgium, Denmark, Finland, France, Germany, Greece, Ireland, Italy, the Netherlands, Norway, Portugal, Spain, Sweden, Switzerland, and the United Kingdom.

The Japanese factors and portfolios include only Japan.

The Asia Pacific ex-Japan factors and portfolios include Australia, Hong Kong, New Zealand, and Singapore.

The North American factors and portfolios include Canada and the United States.

Primary residences include mobile homes and their sites, the parts of farms and ranches not used for farming or ranching business, condominiums, cooperatives, townhouses, other single-family forms, and other permanent dwellings.

Other residential property includes second homes, time-shares, one-to four-family rental properties, and other types of residential properties. It also includes outstanding balances on loans that the family may have made to finance the sale of properties they previously owned and which are still owed to the family.

Nonresidential real estate includes the following types of properties unless they are owned through a business: commercial property, rental property with five or more units, farm and ranch land, undeveloped land, and all other types of nonresidential real estate.

Business equity includes net worth in the following forms of business: sole proprietorships, limited partnerships, other types of partnerships, S corporations and other types of corporations that are not publicly traded, limited liability companies, and other types of private businesses.

Table 6. Excess Bitcoin return in the U.S. (using weekly data from Oanda.com)

\begin{tabular}{lcc}
\hline & $(1)$ & $(2)$ \\
& CAPM & FF-3f model \\
\hline$R_{m, t}-R_{f, t}$ & 0.170 & 0.210 \\
& $(0.26)$ & $(0.29)$ \\
$S M B_{t}$ & & -0.186 \\
& & $(0.12)$ \\
$H M L_{t}$ & & -0.252 \\
& & $(0.15)$ \\
Constant & $5.702^{* * *}$ & $5.686^{* * *}$ \\
& $(4.23)$ & $(4.18)$ \\
Observations & 213 & 213 \\
R-squared & 0.000 & 0.000 \\
\hline
\end{tabular}

Dependent variables are excess Bitcoin returns. t values are in parentheses.

$* * * \mathrm{p}<0.01, * * \mathrm{p}<0.05, * \mathrm{p}<0.1$.

Table 7. Excess Bitcoin return (using monthly data from Oanda.com)

\begin{tabular}{|c|c|c|c|c|c|c|c|c|}
\hline & \multicolumn{2}{|c|}{ The U.S. } & \multicolumn{2}{|c|}{ Asia Pacific $^{+}$} & \multicolumn{2}{|c|}{ Europe } & \multicolumn{2}{|c|}{ Global $^{++}$} \\
\hline & CAPM & FF-3f model & CAPM & FF-3f model & CAPM & FF-3f model & CAPM & FF-3f model \\
\hline \multirow{2}{*}{$R_{m, t}-R_{f, t}$} & -0.773 & -2.192 & -1.572 & -1.893 & -1.569 & -1.433 & -1.169 & -0.874 \\
\hline & $(0.22)$ & $(0.52)$ & $(0.67)$ & $(0.77)$ & $(0.68)$ & $(0.50)$ & $(0.42)$ & $(0.28)$ \\
\hline \multirow{2}{*}{$S M B_{t}$} & & 5.257 & & -8.704 & & -0.065 & & 0.655 \\
\hline & & $(0.67)$ & & $(1.31)$ & & $(0.01)$ & & $(0.07)$ \\
\hline \multirow{2}{*}{$H M L_{t}$} & & -6.290 & & -2.149 & & -0.547 & & -2.201 \\
\hline & & $(0.78)$ & & $(0.27)$ & & $(0.09)$ & & $(0.26)$ \\
\hline \multirow{2}{*}{ Constant } & $38.189 * * *$ & $40.224 * * *$ & $38.618 * * *$ & $37.182 * * *$ & $38.821 * * *$ & $38.631 * * *$ & $38.199 * * *$ & $38.294 * * *$ \\
\hline & $(2.80)$ & (2.86) & (3.04) & $(2.83)$ & (3.04) & (2.90) & (2.97) & $(2.90)$ \\
\hline Observations & 47 & 47 & 47 & 47 & 47 & 47 & 47 & 47 \\
\hline $\mathrm{R}$-squared & 0.000 & 0.03 & 0.01 & 0.05 & 0.01 & 0.01 & 0.00 & 0.01 \\
\hline
\end{tabular}




\begin{tabular}{lcccccc}
\hline & \multicolumn{2}{c}{ Global } & \multicolumn{2}{c}{ Japan } & \multicolumn{2}{c}{ North America } \\
& CAPM & FF-3f model & CAPM & FF-3f model & CAPM & FF-3f model \\
\hline \multirow{2}{*}{$R_{m, t}-R_{f, t}$} & -1.097 & -0.767 & -1.097 & -0.767 & -0.781 & -1.673 \\
& $(0.35)$ & $(0.24)$ & $(0.35)$ & $(0.24)$ & $(0.23)$ & $(0.40)$ \\
$S M B_{t}$ & & 2.861 & & 2.861 & & 3.732 \\
& & $(0.28)$ & & $(0.28)$ & & $(0.46)$ \\
$H M L_{t}$ & & -7.049 & & -7.049 & & -8.484 \\
& & $(0.74)$ & & $(0.74)$ & & $(1.02)$ \\
Constant & $38.387^{* * *}$ & $39.195^{* * *}$ & $38.387^{* * *}$ & $39.195 * * *$ & $38.153^{* * *}$ & $40.752^{* * *}$ \\
Observations & $(2.92)$ & $(2.93)$ & $(2.92)$ & $(2.93)$ & $(2.82)$ & $(2.90)$ \\
R-squared & 47 & 47 & 47 & 47 & 47 & 47 \\
\hline
\end{tabular}

Dependent variables are excess Bitcoin return. $t$ values are in parentheses. $* * * p<0.01, * * p<0.05, * p<0.1$

${ }^{+}$Japan is excluded in Asia Pacific region. ${ }^{++}$U.S. is excluded in Global region.

Table 8. Optimal portfolio using data from Oanda.com

\begin{tabular}{|c|c|c|c|c|c|}
\hline \multicolumn{6}{|c|}{ Panel A (Using weekly data): } \\
\hline & $\mu_{A}$ & $\operatorname{var}(A)$ & & & \\
\hline \multirow[t]{2}{*}{ Excess Bitcoin return } & 5.61 & 375.302 & & & \\
\hline & $\mu_{B}$ & $\operatorname{var}(B)$ & $\operatorname{cov}(B, A)$ & {$\left[W_{A}\right.$} & $\left.W_{B}\right]$ \\
\hline The U.S. & 0.343 & 4.177 & 0.711 & $16.1 \%$ & $83.9 \%$ \\
\hline \multicolumn{6}{|c|}{ Panel B (Using monthly data): } \\
\hline & $\mu_{A}$ & $\operatorname{var}(A)$ & & & \\
\hline \multirow[t]{2}{*}{ Excess Bitcoin return } & 36.984 & 7234.45 & & & \\
\hline & $\mu_{B}$ & $\operatorname{var}(B)$ & $\operatorname{cov}(B, A)$ & {$\left[W_{A}\right.$} & $\left.W_{B}\right]$ \\
\hline The U.S. & 1.485 & 13.532 & -10.455 & $4.4 \%$ & $95.6 \%$ \\
\hline Asia Pacific ${ }^{+}$ & 0.998 & 28.960 & -45.533 & $11.1 \%$ & $88.9 \%$ \\
\hline Europe & 1.035 & 29.922 & -46.944 & $11.1 \%$ & $88.9 \%$ \\
\hline Global $^{++}$ & 0.949 & 21.079 & -24.649 & $9.4 \%$ & $90.6 \%$ \\
\hline Global & 1.170 & 16.533 & -18.134 & $6.5 \%$ & $93.5 \%$ \\
\hline Japan & 0.800 & 15.106 & 55.337 & $12.1 \%$ & $87.9 \%$ \\
\hline North America & 1.373 & 13.965 & -10.904 & $4.9 \%$ & $95.1 \%$ \\
\hline
\end{tabular}

$A=R_{b, t}-R_{f, t}, B=R_{m, t}-R_{f, t}$ and $\mu_{A}$ is the expect return on excess Bitcoin return.

$\operatorname{var}(A)$ and $\operatorname{var}(B)$ are the variance of excess Bitcoin return and the variance of excess market return.

$\operatorname{cov}(B, A)$ is the covariance of excess market return and excess Bitcoin return.

$\left[W_{A} W_{B}\right]$ is the optimal proportion of Bitcoin and stocks in an investment portfolio.

${ }^{+}$Japan is excluded in Asian Pacific region. ${ }^{++}$U.S. is excluded in Global region.

Table 9. Estimated results using agents' wealth index with weighted assets in year 2010

\begin{tabular}{lcc}
\hline Panel A: & $(1)$ & $(2)$ \\
& CAPM & FF-3f model \\
\hline$R_{m, t}-R_{f, t}$ & 0.039 & -0.469 \\
& $(0.02)$ & $(0.19)$ \\
$S M B_{t}$ & & 3.786 \\
& & $(0.53)$ \\
$H M L_{t}$ & & -6.931 \\
& & $(0.90)$ \\
Constant & $36.477 * * *$ & $37.384^{* * *}$ \\
Observations & $(2.87)$ & $(2.89)$ \\
R-squared & 47 & 47 \\
\hline
\end{tabular}

Dependent variables are excess Bitcoin returns. t values are in parentheses.

$* * * \mathrm{p}<0.01, * * \mathrm{p}<0.05, * \mathrm{p}<0.1$ 


\begin{tabular}{lcccccc}
\hline Panel B & $\mu_{A}$ & $\operatorname{var}(A)$ & & & & \\
& 36.552 & 6669.7981 & & & \\
\hline Excess Bitcoin return & $\mu_{B}$ & $\operatorname{var}(B)$ & $\operatorname{cov}(B, A)$ & {$\left[W_{A}\right.$} & $\left.W_{B}\right]$ \\
\hline The U.S. & 1.987 & 33.091 & 1.317 & $8.4 \%$ & $91.6 \%$ \\
\hline
\end{tabular}

$A=R_{b, t}-R_{f, t}, B=R_{m, t}-R_{f, t}$ and $\mu_{A}$ is the expect return on excess Bitcoin return.

$\operatorname{var}(A)$ and $\operatorname{var}(B)$ are the variance of excess Bitcoin return and the variance of excess market return.

$\operatorname{cov}(B, A)$ is the covariance of excess market return and excess Bitcoin return.

$\left[W_{A} W_{B}\right]$ is the optimal proportion of Bitcoin and stocks in an investment portfolio.

Table 10. Estimated results using agents' wealth index with weighted assets in year 2013

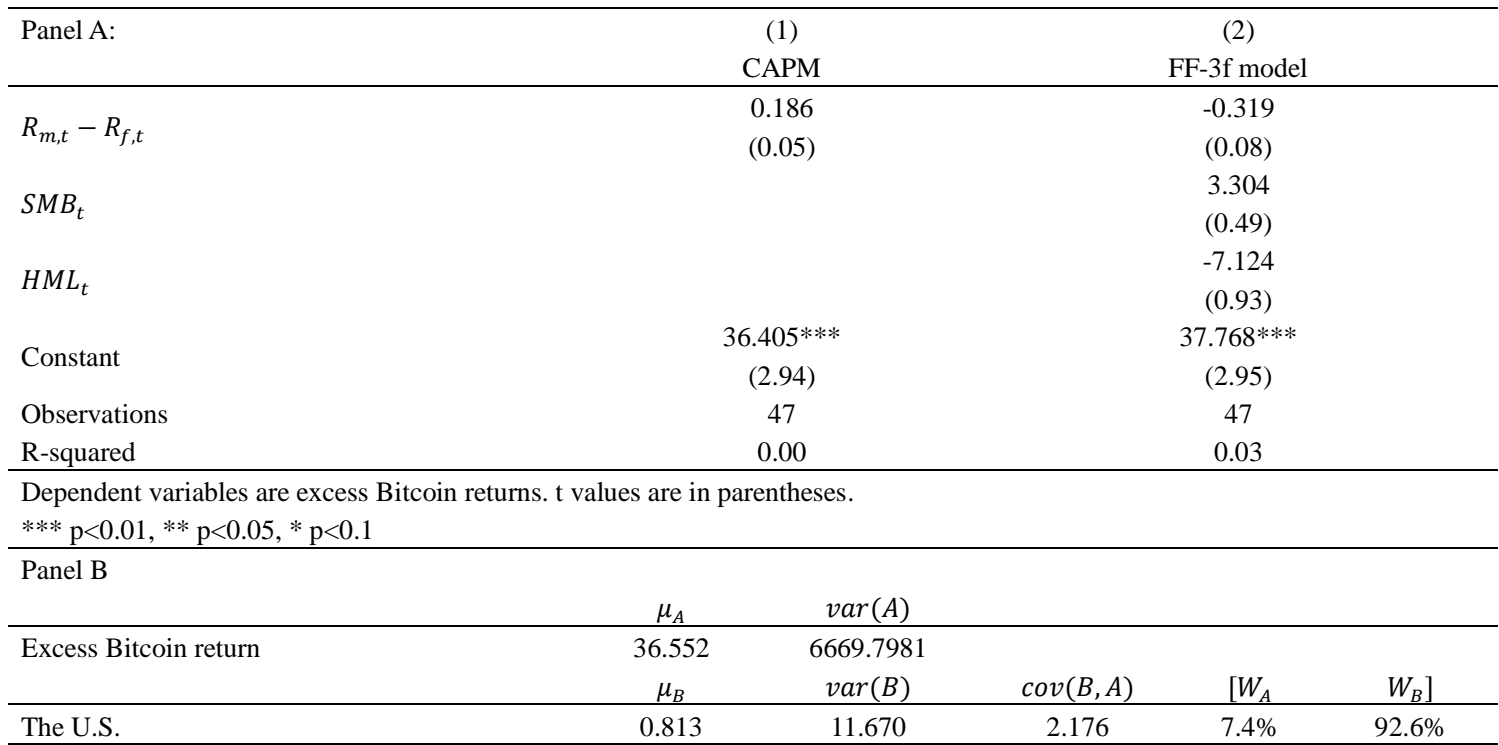

$A=R_{b, t}-R_{f, t}, B=R_{m, t}-R_{f, t}$ and $\mu_{A}$ is the expect return on excess Bitcoin return.

$\operatorname{var}(A)$ and $\operatorname{var}(B)$ are the variance of excess Bitcoin return and the variance of excess market return.

$\operatorname{cov}(B, A)$ is the covariance of excess market return and excess Bitcoin return.

$\left[W_{A} W_{B}\right]$ is the optimal proportion of Bitcoin and stocks in an investment portfolio.

Table 11. Estimated results using daily Bitcoin data from Bitstamp exchange company only

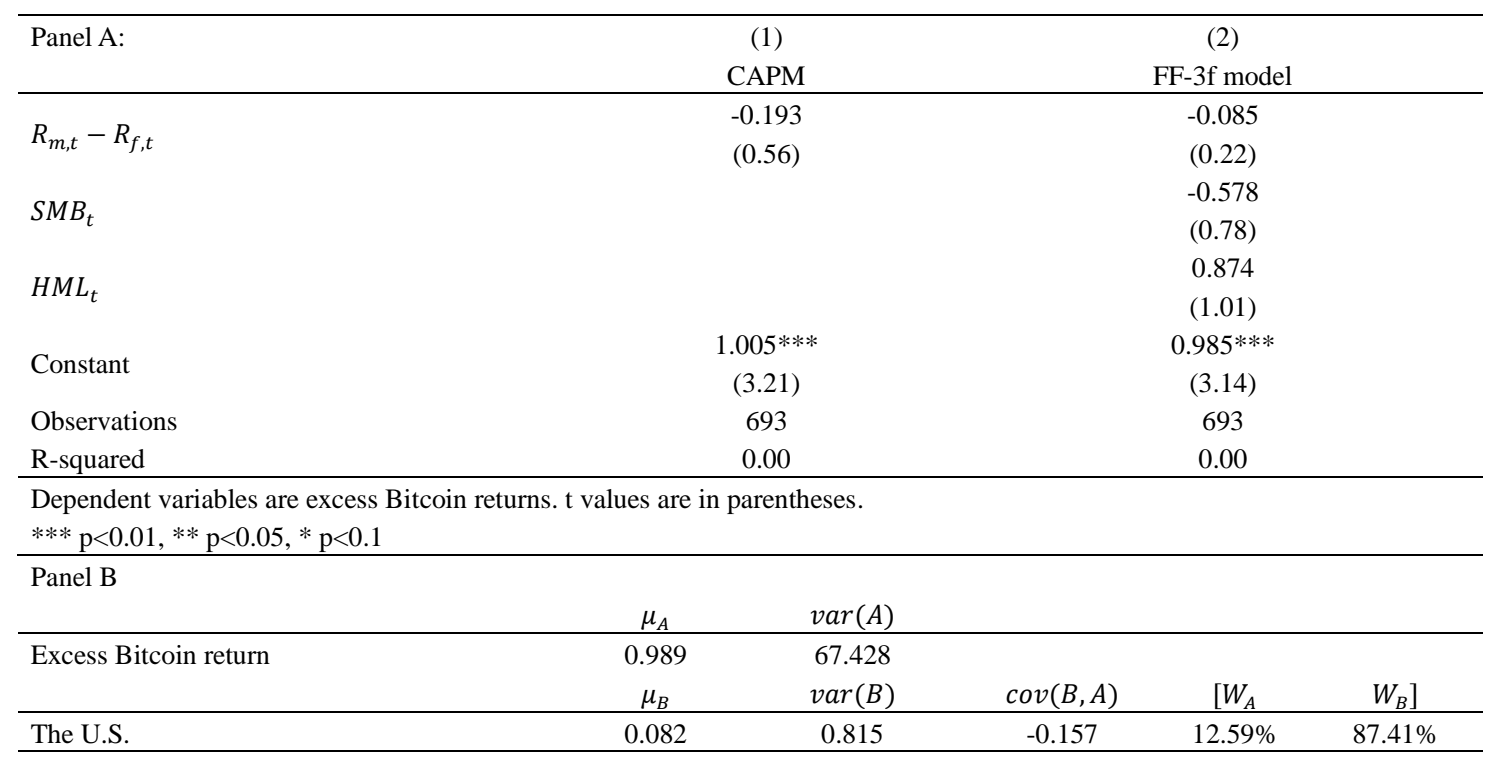

$A=R_{b, t}-R_{f, t}, B=R_{m, t}-R_{f, t}$ and $\mu_{A}$ is the expect return on excess Bitcoin return.

$\operatorname{var}(A)$ and $\operatorname{var}(B)$ are the variance of excess Bitcoin return and the variance of excess market return.

$\operatorname{cov}(B, A)$ is the covariance of excess market return and excess Bitcoin return.

$\left[W_{A} W_{B}\right]$ is the optimal proportion of Bitcoin and stocks in an investment portfolio. 
Table 12. Bitcoin theft cases

\begin{tabular}{lccc}
\hline Time & Company name & Theft value & Number of Bitcoin \\
\hline Late November, 2013 & Sheep Marketplace & $\$ 100$ millions & 5,400 BTC \\
February, 2014 & Silk Road 2 & $\$ 2.7$ millions & $4,474.27$ BTC \\
October, 2013 & TradeFortress & $\$ 1$ millions & 4,100 BTC \\
Late February, 2014 & Mt. Gox & $\$ 350$ millions & 744,000 BTC \\
March, 2014 & Flexcoin & $\$ 654,000$ & 896 BTC \\
March, 2014 & Poloniex & $\$ 50,000$ & 76.59 BTC \\
January, 2015 & Bitstamp & $\$ 5$ millions & 19,000 BTC \\
February, 2015 & BTER & $\$ 1.75$ millions & 7,170 BTC \\
\hline
\end{tabular}

Table 13. Optimal portfolio using data from Coindesk.com incorporate the probability of stolen Bitcoin

\begin{tabular}{lccccc}
\hline Panel A (Using daily data): & \multicolumn{5}{c}{} \\
\hline & $\mu_{A}$ & $\operatorname{var}(A)$ & & & \\
\hline Excess Bitcoin return & 1.121 & 65.786 & & & \\
& $\mu_{B}$ & $\operatorname{var}(B)$ & $\operatorname{cov}(B, A)$ & {$\left[W_{A}\right.$} & $\left.W_{B}\right]$ \\
\hline The U.S. & 0.076 & 1.061 & 0.440 & $20.3 \%$ & $79.7 \%$ \\
Panel B (Using monthly data): & & & & & \\
\hline & $\mu_{A}$ & $\operatorname{var}(A)$ & & & \\
\hline Excess Bitcoin return & 36.984 & 7234.45 & & & \\
& $\mu_{B}$ & $\operatorname{var}(B)$ & $\operatorname{cov}(B, A)$ & {$\left[W_{A}\right.$} & \\
\hline The U.S. & 1.485 & 13.946 & 0.617 & $4.8 \%$ & $95.2 \%$ \\
Asia Pacific ${ }^{+}$ & 0.998 & 28.425 & -35.305 & $11.8 \%$ & $88.2 \%$ \\
Europe & 1.035 & 29.300 & -25.034 & $12.2 \%$ & $87.8 \%$ \\
Global & & & & \\
Global & 0.949 & 21.023 & -9.835 & $10.3 \%$ & $89.7 \%$ \\
Japan & 1.170 & 16.746 & -4.042 & $7.1 \%$ & $92.9 \%$ \\
North America & 0.800 & 15.032 & 57.026 & $13.1 \%$ & $86.9 \%$ \\
\hline
\end{tabular}

$A=R_{b, t}-R_{f, t}, B=R_{m, t}-R_{f, t}$ and $\mu_{A}$ is the expect return on excess Bitcoin return.

$\operatorname{var}(A)$ and $\operatorname{var}(B)$ are the variance of excess Bitcoin return and the variance of excess market return.

$\operatorname{cov}(B, A)$ is the covariance of excess market return and excess Bitcoin return.

$\left[W_{A} W_{B}\right]$ is the optimal proportion of Bitcoin and stocks in an investment portfolio.

${ }^{+} J a p a n$ is excluded in Asian Pacific region. ${ }^{++}$U.S. is excluded in Global region.

Table 14. Excess gold return in the US dollars

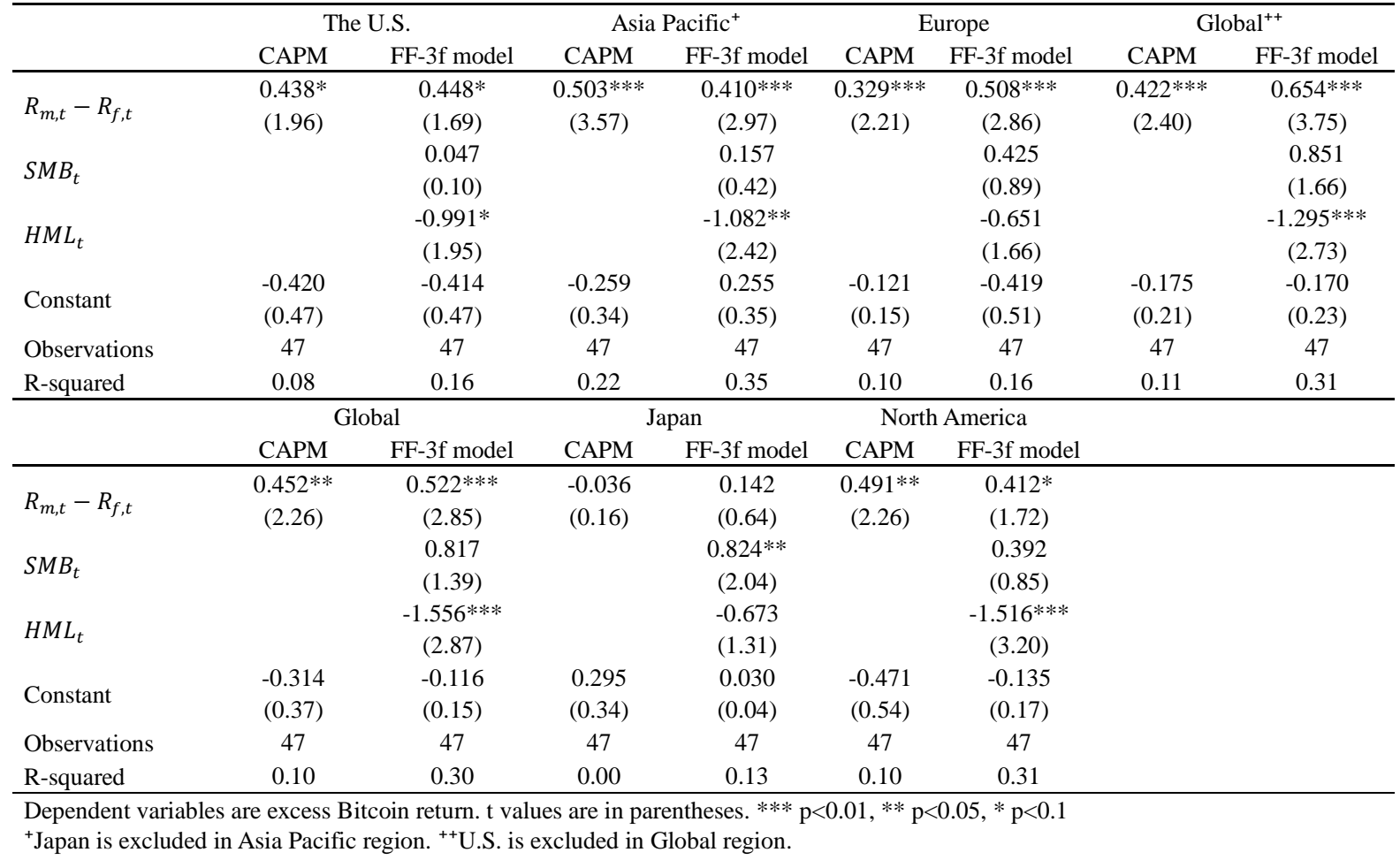


Table 15. Stock market capitalization by countries in 2012

\begin{tabular}{lclclc}
\hline Country & Billion USD & Country & Billions USD & Country & Billions USD \\
\hline Australia & 1286 & Greece & 45 & Portugal & 66 \\
Austria & 106 & Hong Kong & 1108 & Singapore & 414 \\
Belgium & 300 & Ireland & 109 & Spain & 995 \\
Canada & 2016 & Italy & 480 & Switzerland & 1079 \\
Denmark & 255 & Japan & 3681 & Sweden & 561 \\
Finland & 159 & Netherlands & 651 & United Kingdom & 3019 \\
France & 1823 & New Zealand & 80 & United States & 18668 \\
Germany & 1486 & Norway & 253 & & \\
\hline
\end{tabular}

Table 16. Market portfolio incorporated with Bitcoin based on stock market capitalizations in 2012

\begin{tabular}{|c|c|c|c|c|c|}
\hline & \multirow{2}{*}{$\begin{array}{c}\text { Market capitalization in } \\
\text { Billion USD }\end{array}$} & \multicolumn{2}{|c|}{ Bitcoin capitalization in 2012} & \multicolumn{2}{|c|}{ Bitcoin capitalization in 2015} \\
\hline & & $\%$ of Bitcoin & $\%$ of stock market & $\%$ of Bitcoin & $\%$ of stock market \\
\hline Bitcoin in 2012 & 0.0815 & & & & \\
\hline Bitcoin in 2015 & 5.4 & & & & \\
\hline The U.S. & 18668 & $0.0004 \%$ & $99.9996 \%$ & $0.0289 \%$ & $99.9711 \%$ \\
\hline Asia Pacific ${ }^{+}$ & 2888 & $0.0028 \%$ & $99.9972 \%$ & $0.1870 \%$ & $99.8130 \%$ \\
\hline Europe & 11357 & $0.0007 \%$ & $99.9993 \%$ & $0.0475 \%$ & $99.9525 \%$ \\
\hline Global $^{++}$ & 19942 & $0.0004 \%$ & $99.9996 \%$ & $0.0271 \%$ & $99.9729 \%$ \\
\hline Global & 38610 & $0.0002 \%$ & $99.9998 \%$ & $0.0140 \%$ & $99.9860 \%$ \\
\hline Japan & 3681 & $0.0022 \%$ & $99.9978 \%$ & $0.1467 \%$ & $99.8533 \%$ \\
\hline North America & 20684 & $0.0004 \%$ & $99.9996 \%$ & $0.0261 \%$ & $99.9739 \%$ \\
\hline
\end{tabular}

${ }^{+}$Japan is excluded in Asia Pacific region. ${ }^{++}$U.S. is excluded in Global region.

Table 17. Excess Bitcoin return in the U.S. (using daily data from coindesk.com and the market portfolio incorporated with Bitcoin. The weight of Bitcoin in the market portfolio is $0.0004 \%$, based on Bitcoin capitalization in 2012)

\begin{tabular}{lcc}
\hline & $(1)$ & $(2)$ \\
& CAPM & FF-3f model \\
\hline$R_{m, t}-R_{f, t}$ & $0.440^{*}$ & 0.243 \\
& $(1.72)$ & $(0.80)$ \\
$S M B_{t}$ & & 0.563 \\
& & $(0.90)$ \\
$H M L_{t}$ & & 1.169 \\
& & $(1.63)$ \\
Constant & $1.208^{* * *}$ & $1.218^{* * *}$ \\
Observations & $(4.57)$ & $(4.61)$ \\
R-squared & 994 & 994 \\
\hline
\end{tabular}

Dependent variables are excess Bitcoin returns. t values are in parentheses. $* * * \mathrm{p}<0.01, * * \mathrm{p}<0.05,{ }^{*} \mathrm{p}<0.1$.

Table 18. Excess Bitcoin return in the U.S. (using daily data from coindesk.com and the market portfolio incorporated with Bitcoin. The weight of Bitcoin in the market portfolio is $0.0289 \%$, based on Bitcoin capitalization in 2015)

\begin{tabular}{|c|c|c|}
\hline & $\begin{array}{c}(1) \\
\text { CAPM }\end{array}$ & $\begin{array}{c}\text { (2) } \\
\text { FF-3f model }\end{array}$ \\
\hline$R_{m, t}-R_{f, t}$ & $\begin{array}{c}0.459^{*} \\
(1.79)\end{array}$ & $\begin{array}{l}0.269 \\
(0.88)\end{array}$ \\
\hline$S M B_{t}$ & & $\begin{array}{l}0.535 \\
(0.86)\end{array}$ \\
\hline$H M L_{t}$ & & $\begin{array}{l}1.156 \\
(1.61)\end{array}$ \\
\hline Constant & $\begin{array}{c}1.207 * * * \\
(4.56)\end{array}$ & $\begin{array}{c}1.216^{* * * *} \\
(4.60)\end{array}$ \\
\hline Observations & 994 & 994 \\
\hline R-squared & 0.00 & 0.01 \\
\hline
\end{tabular}

Dependent variables are excess Bitcoin returns. t values are in parentheses. $* * * \mathrm{p}<0.01,{ }^{*} \mathrm{p}<0.05,{ }^{*} \mathrm{p}<0.1$. 
Table 19. Excess Bitcoin return (using monthly data from coindesk.com and the market portfolio incorporated with Bitcoin. The weight of Bitcoin in the market portfolio is $0.0004 \%$, based on Bitcoin capitalization in 2012)

\begin{tabular}{|c|c|c|c|c|c|c|c|c|}
\hline & \multicolumn{2}{|c|}{ The U.S. } & \multicolumn{2}{|c|}{ Asia Pacific ${ }^{+}$} & \multicolumn{2}{|c|}{ Europe } & \multicolumn{2}{|c|}{ Global $^{++}$} \\
\hline & CAPM & FF-3f model & CAPM & FF-3f model & CAPM & FF-3f model & CAPM & FF-3f model \\
\hline \multirow{2}{*}{$R_{m, t}-R_{f, t}$} & -0.154 & -1.336 & -1.363 & -1.682 & -1.072 & -0.856 & -0.663 & -0.474 \\
\hline & $(0.05)$ & $(0.33)$ & $(0.61)$ & $(0.71)$ & $(0.48)$ & $(0.31)$ & $(0.25)$ & $(0.16)$ \\
\hline \multirow{2}{*}{$S M B_{t}$} & & 4.493 & & -8.377 & & -0.378 & & -0.293 \\
\hline & & $(0.60)$ & & $(1.31)$ & & $(0.05)$ & & $(0.03)$ \\
\hline \multirow{2}{*}{$H M L_{t}$} & & -6.696 & & -2.187 & & -0.908 & & -2.294 \\
\hline & & $(0.87)$ & & $(0.29)$ & & $(0.15)$ & & $(0.28)$ \\
\hline \multirow{2}{*}{ Constant } & $36.793 * * *$ & $38.514 * * *$ & $37.980 * * *$ & $36.640 * * *$ & $37.807 * * *$ & $37.530 * * *$ & $37.241 * * *$ & $37.445 * * *$ \\
\hline & $(2.81)$ & $(2.85)$ & $(3.11)$ & $(2.90)$ & (3.08) & $(2.93)$ & (3.02) & $(2.95)$ \\
\hline Observations & 47 & 47 & 47 & 47 & 47 & 47 & 47 & 47 \\
\hline \multirow[t]{3}{*}{ R-squared } & 0.00 & 0.03 & 0.01 & 0.05 & 0.01 & 0.01 & 0.00 & 0.00 \\
\hline & \multicolumn{2}{|c|}{ Global } & \multicolumn{2}{|c|}{ Japan } & \multicolumn{2}{|c|}{ North America } & & \\
\hline & CAPM & FF-3f model & CAPM & FF-3f model & CAPM & FF-3f model & & \\
\hline \multirow{2}{*}{$R_{m, t}-R_{f, t}$} & -0.508 & -0.148 & 3.909 & 3.895 & -0.206 & -0.857 & & \\
\hline & $(0.17)$ & $(0.05)$ & (1.27) & (1.17) & $(0.06)$ & $(0.21)$ & & \\
\hline \multirow{2}{*}{$S M B_{t}$} & & 1.780 & & -1.800 & & 2.943 & & \\
\hline & & $(0.18)$ & & $(0.30)$ & & $(0.38)$ & & \\
\hline \multirow{2}{*}{$H M L_{t}$} & & -7.255 & & -1.857 & & -8.975 & & \\
\hline & & $(0.79)$ & & $(0.24)$ & & (1.13) & & \\
\hline \multirow{2}{*}{ Constant } & $37.202 * * *$ & $37.906 * * *$ & $33.138 * *$ & $33.933 * *$ & $36.861 * * *$ & $39.144 * * *$ & & \\
\hline & (2.94) & (2.95) & $(2.73)$ & (2.69) & $(2.84)$ & (2.90) & & \\
\hline Observations & 47 & 47 & 47 & 47 & 47 & 47 & & \\
\hline R-squared & 0.00 & 0.02 & 0.03 & 0.04 & 0.00 & 0.04 & & \\
\hline
\end{tabular}

Dependent variables are excess Bitcoin return. $t$ values are in parentheses. $* * * p<0.01, * * \mathrm{p}<0.05, * \mathrm{p}<0.1$

${ }^{+}$Japan is excluded in Asia Pacific region. ${ }^{++}$U.S. is excluded in Global region.

Table 20. Excess Bitcoin return (using monthly data from coindesk.com and the market portfolio incorporated with Bitcoin. The weight of Bitcoin in the market portfolio is $0.0289 \%$, based on Bitcoin capitalization in 2015)

\begin{tabular}{|c|c|c|c|c|c|c|c|c|}
\hline & \multicolumn{2}{|c|}{ The U.S. } & \multicolumn{2}{|c|}{ Asia Pacific $^{+}$} & \multicolumn{2}{|c|}{ Europe } & \multicolumn{2}{|c|}{ Global $^{++}$} \\
\hline & CAPM & FF-3f model & CAPM & FF-3f model & CAPM & FF-3f model & CAPM & FF-3f model \\
\hline$R_{m, t}-R_{f, t}$ & $\begin{array}{l}-0.014 \\
(0.00)\end{array}$ & $\begin{array}{l}-1.135 \\
(0.28)\end{array}$ & $\begin{array}{l}-0.944 \\
(0.42)\end{array}$ & $\begin{array}{l}-1.240 \\
(0.52)\end{array}$ & $\begin{array}{l}-0.969 \\
(0.44)\end{array}$ & $\begin{array}{l}-0.704 \\
(0.26)\end{array}$ & $\begin{array}{l}-0.579 \\
(0.22)\end{array}$ & $\begin{array}{l}-0.373 \\
(0.13)\end{array}$ \\
\hline$S M B_{t}$ & & $\begin{array}{l}4.282 \\
(0.57)\end{array}$ & & $\begin{array}{r}-8.204 \\
(1.28)\end{array}$ & & $\begin{array}{c}-0.329 \\
(0.04)\end{array}$ & & $\begin{array}{r}-0.199 \\
(0.02)\end{array}$ \\
\hline$H M L_{t}$ & & $\begin{array}{l}-6.778 \\
(0.88)\end{array}$ & & $\begin{array}{l}-1.756 \\
(0.23)\end{array}$ & & $\begin{array}{l}-1.096 \\
(0.18)\end{array}$ & & $\begin{array}{l}-2.359 \\
(0.29)\end{array}$ \\
\hline Constant & $\begin{array}{c}36.574 * * * \\
(2.79)\end{array}$ & $\begin{array}{c}38.228 * * * \\
(2.82)\end{array}$ & $\begin{array}{c}37.596 * * * \\
(3.06)\end{array}$ & $\begin{array}{c}36.163 * * * \\
(2.85)\end{array}$ & $\begin{array}{c}37.702 * * * \\
(3.06)\end{array}$ & $\begin{array}{c}37.345 * * * \\
(2.91)\end{array}$ & $\begin{array}{c}37.159 \text { *** } \\
(3.01)\end{array}$ & $\begin{array}{c}37.355^{* * * *} \\
(2.94)\end{array}$ \\
\hline Observations & 47 & 47 & 47 & 47 & 47 & 47 & 47 & 47 \\
\hline \multirow[t]{3}{*}{ R-squared } & 0.00 & 0.03 & 0.00 & 0.04 & 0.00 & 0.01 & 0.00 & 0.00 \\
\hline & \multicolumn{2}{|c|}{ Global } & \multicolumn{2}{|c|}{ Japan } & \multicolumn{2}{|c|}{ North America } & & \\
\hline & CAPM & FF-3f model & CAPM & FF-3f model & CAPM & FF-3f model & & \\
\hline$R_{m, t}-R_{f, t}$ & $\begin{array}{l}-0.453 \\
(0.15)\end{array}$ & $\begin{array}{l}-0.091 \\
(0.03)\end{array}$ & $\begin{array}{l}4.499 \\
(1.48)\end{array}$ & $\begin{array}{l}4.559 \\
(1.38)\end{array}$ & $\begin{array}{l}-0.083 \\
(0.03)\end{array}$ & $\begin{array}{l}-0.681 \\
(0.17)\end{array}$ & & \\
\hline$S M B_{t}$ & & $\begin{array}{l}1.764 \\
(0.18)\end{array}$ & & $\begin{array}{c}-1.529 \\
(0.26)\end{array}$ & & $\begin{array}{l}2.747 \\
(0.36)\end{array}$ & & \\
\hline$H M L_{t}$ & & $\begin{array}{c}-7.284 \\
(0.80)\end{array}$ & & $\begin{array}{l}-2.229 \\
(0.29)\end{array}$ & & $\begin{array}{l}-9.040 \\
(1.14)\end{array}$ & & \\
\hline Constant & $\begin{array}{c}37.133 * * * \\
(2.94)\end{array}$ & $\begin{array}{c}37.837 * * * * \\
(2.94)\end{array}$ & $\begin{array}{c}32.391 * * \\
(2.68)\end{array}$ & $\begin{array}{c}33.107 * * \\
(2.63)\end{array}$ & $\begin{array}{c}36.678 * * * \\
(2.82)\end{array}$ & $\begin{array}{c}38.889 * * * \\
(2.88)\end{array}$ & & \\
\hline Observations & 47 & 47 & 47 & 47 & 47 & 47 & & \\
\hline R-squared & 0.00 & 0.02 & 0.05 & 0.05 & 0.00 & 0.04 & & \\
\hline
\end{tabular}

Dependent variables are excess Bitcoin return. $\mathrm{t}$ values are in parentheses. ${ }^{* * *} \mathrm{p}<0.01,{ }^{*} \mathrm{p}<0.05,{ }^{*} \mathrm{p}<0.1$.

${ }^{+}$Japan is excluded in Asia Pacific region. ${ }^{++}$U.S. is excluded in Global region. 
Table 21. Optimal portfolio using data from Coindesk.com. The market portfolio incorporated with Bitcoin, and the weight of Bitcoin in the market portfolio is $0.0004 \%$, based on Bitcoin market capitalization in 2012

\begin{tabular}{|c|c|c|c|c|c|}
\hline \multicolumn{6}{|l|}{ Panel A (Using daily data): } \\
\hline & $\mu_{A}$ & $\operatorname{var}(A)$ & & & \\
\hline \multirow[t]{2}{*}{ Excess Bitcoin return } & 1.242 & 69.270 & & & \\
\hline & $\mu_{B}$ & $\operatorname{var}(B)$ & $\operatorname{cov}(B, A)$ & {$\left[W_{A}\right.$} & $\left.W_{B}\right]$ \\
\hline The U.S. & 0.076 & 1.060 & 0.494 & $21.5 \%$ & $78.5 \%$ \\
\hline \multicolumn{6}{|l|}{ Panel B (Using monthly data): } \\
\hline & $\mu_{A}$ & $\operatorname{var}(A)$ & & & \\
\hline \multirow[t]{2}{*}{ Excess Bitcoin return } & 36.552 & 6669.7981 & & & \\
\hline & $\mu_{B}$ & $\operatorname{var}(B)$ & $\operatorname{cov}(B, A)$ & {$\left[W_{A}\right.$} & $\left.W_{B}\right]$ \\
\hline The U.S. & 1.485 & 13.946 & -2.088 & $4.89 \%$ & $95.11 \%$ \\
\hline Asia Pacific ${ }^{+}$ & 0.998 & 28.425 & -39.476 & $11.75 \%$ & $88.25 \%$ \\
\hline Europe & 1.035 & 29.300 & -32.061 & $12.03 \%$ & $87.97 \%$ \\
\hline Global $^{++}$ & 0.949 & 21.023 & -13.971 & $10.26 \%$ & $89.74 \%$ \\
\hline Global & 1.170 & 16.746 & -8.405 & $7.12 \%$ & $92.88 \%$ \\
\hline Japan & 0.800 & 15.032 & 59.058 & $13.63 \%$ & $86.37 \%$ \\
\hline North America & 1.373 & 14.407 & -2.877 & $5.4 \%$ & $94.6 \%$ \\
\hline
\end{tabular}

$A=R_{b, t}-R_{f, t}, B=R_{m, t}-R_{f, t}$ and $\mu_{A}$ is the expect return on excess Bitcoin return.

$\operatorname{var}(A)$ and $\operatorname{var}(B)$ are the variance of excess Bitcoin return and the variance of excess market return.

$\operatorname{cov}(B, A)$ is the covariance of excess market return and excess Bitcoin return.

$\left[W_{A} W_{B}\right]$ is the optimal proportion of Bitcoin and stocks in an investment portfolio.

${ }^{+}$Japan is excluded in Asian Pacific region. ${ }^{++}$U.S. is excluded in Global region.

\section{Copyrights}

Copyright for this article is retained by the author(s), with first publication rights granted to the journal.

This is an open-access article distributed under the terms and conditions of the Creative Commons Attribution license (http://creativecommons.org/licenses/by/4.0/). 